\title{
An examination of theory and promising practice for achieving permanency for teens before they age out of foster care
}

\author{
Rosemary J. Avery* \\ Department of Policy Analysis and Management, Cornell University, 119 MVR Hall, Cornell University, Ithaca, NY 14853, United States
}

\section{A R T I C L E I N F O}

\section{Article history:}

Received 29 July 2009

Received in revised form 18 October 2009

Accepted 20 October 2009

Available online 28 October 2009

\section{Keywords:}

Permanency

Teens

Foster care

Independent living

Promising practice

\begin{abstract}
A B S T R A C T
In this paper research is presented that examines the efficacy of Independent Living (IL) services in preparing foster youth to live "independently", and calls into question the appropriateness of an "independence" goal for youth aging out of foster care. The paper then reviews the emerging conceptualization of youth permanency in child welfare practice that focuses on lifelong connections to kin and fictive kin as requirements for permanency. The paper then reports on the success of a federally-funded demonstration project that served youth in residential treatment facilities and group homes in New York City aging out of care. It examines elements of the project model that were highly successful in achieving family-based permanency for a significant proportion of youth referred to the program and concludes that it is a promising practice model for the profession.
\end{abstract}

(c) 2009 Elsevier Ltd. All rights reserved.

\section{Introduction}

The majority of youth who age out of foster care face enormous challenges. Many leave care disconnected from supportive adults, services, and socioeconomic supports that would significantly increase their chances of becoming productive, self-sustaining adults (Metzger, 2006). Research indicates that youth who age out of foster care to "independent living" are more likely to experience homelessness, unemployment, unplanned pregnancy, legal system involvement, substance abuse, and lack even the basic health care services. They also are less likely to have a high school diploma, earn enough to support themselves, or participate in post-secondary education or training (Courtney, Dwosrky, Ruth, Havlick \& Bost, 2005). Foster care support, which provides housing, financial support, and a range of health, education and other needed services, typically ends when youth are developmentally unprepared to assume full adult roles and responsibilities. Furthermore, Independent Living (IL) programs have proven inadequate to prepare youth for "independence" in any meaningful way. Too many youth leave care unconnected to committed adults in their lives who could buffer the challenges they face and serve as safe havens in times of need.

Increasing policy, program, and practice attention are being devoted to developing new strategies to enhance the capacities of youth emancipating from foster care to achieve better outcomes. The Adoption and Safe Families Act of 1997 and, most recently, the Fostering Connections to Success and Increasing Adoptions Act of

* Tel.: +16072552578 (w); +16072770776 (h); +1 6075921513 (c); fax: +1 6072554071.

E-mail address: rja7@cornell.edu.
2008 have strengthened the mandate that each youth leave foster care with a permanent family through safe reunification with their parents, adoption, guardianship, or that they have "another planned permanent living arrangement" (Center for the Study of Law and Social Policy, 2008). The Fostering Connections to Success and Increasing Adoptions Act of 2008 provides several tools for prioritizing family connections. The bill gives states the option of extending financial supports to kin providers and older youth. It includes new mandates for notifying kin, analyzing the use of kin foster care, and explaining foster care benefits and requirements to kin (Kerman \& Glasheen, 2009).

Until recently, however, the issue of permanence for youth has lacked sufficient attention in the child welfare community and misconceptions about the issue abound, including that people do not want to adopt teens, teens do not want to be adopted, and that placements of teens are unsuccessful (Louisell, 2009). Furthermore, despite the rapidly burgeoning research literature on youth leaving care, there has been surprisingly little attention paid to the reconnection of former foster youth with birth families and other kin in the post care period. The empirical findings are scattered and often hidden in studies examining outcomes for former foster youth and the evaluation of IL programs (Collins, Paris, \& Ward, 2008). Moreover, there has been little or no attention paid to wellestablished theories of child development that shed serious doubt on the assumption of age 18 as the appropriate life-marker transition age for "adulthood" and launching foster youth into independence.

There is an abundance of research indicating that successful youth development is inextricably linked to relationships with the family of origin and other fictive kin that influence developmental trajectories and life changes in adulthood (Arnett \& Tanner, 2006; Cooney \& Kurz, 
1996). Adolescents on the path to adulthood rely upon their families for myriad forms of support, support that is critically important to their development and future life outcomes. Reestablishing these family connection for teens before they exit out of foster care, no matter what age they are, is the strongest and most positive youth development program the child welfare system can offer, and it is imperative that child welfare professionals identify 'promising practice' service models that are effective at achieving this outcome for teens if the goals of the Fostering Connections to Success and Increasing Adoptions Act of 2008 are to be met.

In this paper research from developmental and socio-psychology on the transition into adulthood for the general U.S. population is examined. This research will indicate that the transition to adulthood is a gradual process for most adolescents, unrelated to a specific nominal age, and that true "adult" functioning in terms of cognitive, behavioral, and social maturity is not achieved for the majority of emerging adults until the third decade of life. Next research is examined from the child development literature on the critical role of social capital (parents, kin, social supports) in guiding and supporting youth during this transition to adulthood and the deleterious consequences for them when this support is absent. Then, turning the attention to the child welfare system, research is presented that examines the efficacy and adequacy of IL services in preparing youth to live "independently", and calls into question the appropriateness of an "independence" goal for any youth in care. The paper then reviews a new conceptualization of youth permanency that appears to be gaining greater currency within the profession, one that is reframing the concept of "permanency" for youth in care in terms of lifelong connections to kin and fictive kin. But, while this new philosophy is emerging, the paper notes that effective practice models for finding permanent parents for teens before they age out of care still lag behind changing conceptualizations. The Children's Bureau (Department of Health and Human Services (DHHS)) views the development of these effective service models as critical to practice change within the profession and has made it a priority funding area for demonstration projects. This paper reports on the success of one such federally-funded demonstration project that serviced youth in residential treatment facilities and group homes in New York City. It examines elements of the project model that were highly successful in achieving family-based permanency for a significant proportion of youth referred to the program and concludes that it is a "promising practice" model for the profession.

\section{Emerging adulthood and home leaving}

During the latter half of the 20th century and into the first decade of the 21st century, the transition to adulthood for U.S. teens has become longer, more complex, uncertain, and diverse (Arnett, 2007). The median age for completing school, marrying, and becoming a parent has steadily risen, and young adults well into their 20s continue to juggle work and school, live at home longer, and delay marriage and their own nuclear family formation. Although the median age at which adolescents first leave home is about 19years, $40 \%$ of those who leave home for the first time between the ages of 18 and 24 return to live in their parental household at some time thereafter, although usually for only a temporary period. About $25 \%$ of children do not leave home for the first time until age 22 or later (Aquilino, 1996). Furthermore, the economic demands for, and returns to, education have increased relentlessly during the past four decades. In response, young people have delayed the assumption of adult roles until their education has been completed, and the data indicate a shrinking fraction of young people entering full-time work before their early twenties, and a growing number doing so only toward the end of their twenties (Furstenberg, Rumbaut, \& Settersten, 2005).
Arnett (2007) conceptualizes the transition from adolescence into adulthood as "emerging adulthood". He describes the period from (roughly) 18 to 25 as a period in the life course with certain common features, different in important ways from adolescence that precedes it and young adulthood that follows it. He describes this period as one in which progress toward independence is made rather than achieved. Arnett and Taber (1994) identify three developmental domains in which these transitions to adulthood take place: the cognitive domain, which is characterized by the development of adult reasoning that includes not only logical reasoning but also subjective feelings and personal experiences, a sense of responsibility to others, and interdependence within a larger society; the emotional domain, which is characterized by the development of autonomy from one's parents (not complete separation but mutuality and reciprocity as equal adults) and the ability to establish intimacy in adult relationships; and the behavioral domain, which is characterized by the establishment of firm impulse control and complying with social conventions.

Arnett and Tanner's (2006) conceptualization of emerging adulthood is backed up by empirical research. Work by Cohen, Kasen, Chen, Hartmark, and Gordon (2003) highlights the gradual nature of the transition to adulthood. They found linear increases over time in the dimensions of independence in residential, financial, romantic, and parenting domains for both males and females, and the consolidation of adult status closer to the end of the third decade of life (late 20s) rather than the second (late teens). Other research has found that cognitive-emotional-behavioral development often continues in important ways during emerging adulthood, and that the period is one of especially heightened vulnerability resulting from disjunctions between the developing brain and behavioral/cognitive systems that mature along different timetables under the control of both common and independent biological processes (Steinberg, 2005).

Further research has found that even though adolescents may be able to show the same level of cognitive ability as adults in making decisions, they may make different decisions because they are more likely than adults to be affected by psychological factors, such as emotions of the moment and the desire to be accepted by peers. The evidence suggests that emerging adults experience difficulty maintaining balanced cognitive-emotional representations, especially if emotions are strongly activated, as when issues of security and survival are threatened (Arnett \& Tanner, 2006). Findings from studies by Greenberg, Schimel, Martens, Solomon, and Pyszczynski (2001), and Pyszczynski, Greenberg, and Solomon (1999) suggest that emerging adults continue to be easily swayed by their emotions, which distort thinking in self-serving and self-protective ways.

In terms of the ability to maintain healthy and balanced interpersonal relationships, research has found that higher levels of ego development (usually achieved during the later stages of emerging adulthood) are related to greater skill in negotiating needs for autonomy/relatedness and in balancing relationship dimensions in close peer and intimate relationships (Schultz \& Selman, 1998). A study by Scharf, Mayseless, and Kivenson-Baron (2004) examined the association between attachment representations and successful coping with developmental tasks of emerging adulthood. These tasks included coping effectively with the homeleaving transition, advancing in the development of the capacity for mature intimacy in friendships and romantic relationships while maintaining close and autonomous relationships with parents, and developing a sense of efficacy and individuation. They found that although these developmental tasks begin to evolve before late adolescence, they are a more central and salient part of emerging adulthood functioning during the third decade of life (late 20s).

This evidence from developmental research cited above on young teen's transitions to adulthood, including their living arrangements, educational patterns, and entry into the work force indicates that few 
young people in the U.S. are ready to assume adult roles and live "independently" before their mid-twenties. Despite these findings which support a phased and delayed transition to adulthood for young people extending well into the third decade of life, child welfare policy in the U.S. continues to convey the expectation that youth in foster care should assume the responsibilities of adulthood at the early age of 18 when they are expected to "age out" of foster care to "independent living". These expectations are inconsistent with the practical reality of young people's lives in the 21st century, and it is essential we hold the same high hopes for youth in foster care as we do for our own children in terms of connections, living situations, and expectations for their future (Louisell, 2009).

\section{The importance of social capital in emerging adulthood}

Successful youth development is inextricably linked to relationships with the family of origin that influence developmental trajectories and life changes in adulthood (Arnett \& Tanner, 2006; Cooney \& Kurz, 1996). The family of origin functions as a base of operations for the explorations that occur prior to adulthood, both literally (through co-residence in a parental household, parental financial subsidies, and other material support) and figuratively (through the availability of parents and kin as sources of wisdom and guidance). Adolescents on the path to early adulthood rely upon their families for myriad forms of support. This support is critically important in the process of identity development, and may be manifest in multiple forms, such as instrumental, emotional, or informational support (Collins, Paris \& Ward, 2008). For example, family relationships guide a young person's expectations, feelings, information processing, as well as emotion regulation in situations that are attachment related (Aquilino, 2006; Scharf, Mayseless, \& Kivenson-Baron, 2004).

Coleman (1990) uses the concept of "social capital" to designate this complex social support system that parents (or significant other adults in the child's life) garner to advance their children's chances of success in life. Social Capital Theory (Coleman, 1990) refers to these relational networks, social trust, and norms as fundamental forms of social capital. Social capital describes an interpersonal resource upon which individuals can draw to enhance their opportunities in life (Putnam, 1995, 2000). It includes obligations, expectations, and trustworthiness embodied in social structures, the potential for information in social relations, and norms and effective sanctions. It is formed as a result of relationships between parents and children, and is enhanced when the family is embedded in social relationships with other families and community institutions. Social capital conveys benefits to individuals within this social network through the provision of information, influence and control, and social solidarity (Sandefur \& Lauman, 1998). Social capital theory emphasizes the importance of social patterns of acceptable behavior that support desirable social outcomes in that they provide for the exchange of information that facilitates outcomes desirable to group. Without social networks there is no possibility for the exchange of information or the enforcement of norms that facilitate collective goals (Goddard, 2003). According to social capital theory individuals engaging in relationships characterized by high levels of social trust are more likely to openly exchange information and to act with caring and benevolence toward one another than those in relationships lacking in trust.

High levels of social capital in a child's life have been linked to more positive life outcomes and productive personal outcomes such as occupational viability, individual health and psychological well being (for a review, see Baker, 2000). Furstenberg and Hughes (1995) showed that social capital, measured as parents' social investments in their children and the community, increases children's odds of graduating from high school and attending college. Findings from longitudinal studies of the associations between parents' support for, and adolescent progress toward, separation-individuation reveal that healthy separation-individuation predicts adolescent adjustment and the ability to gain adult-sufficiency in emerging adulthood (Allen \& Hauser, 1996; Bell, Allen, Hauser \& O'Connor, 1996). Further research has indicated that forms of parental support are correlated with adolescents' sense of self-worth and adjustment (Scholte, van Lieshout, \& van Aken, 2001), and life satisfaction (Young, Miller, Norton, \& Hill, 1995), and that smaller social support networks (less social capital) are associated with higher likelihood of homelessness (Reilly, 2003).

Family relationships influence emerging adults' psychological development (including adjustment to new roles, health and risk-taking behaviors, capacity for intimacy, and identity formation), and autonomous/secure states of mind with regard to attachment relationships emanating from positive parent-child experiences are carried forward into adult intimate relationships and the capacity for establishing healthy adult interpersonal skills (Masten, Obradovic \& Burt, 2006; Scharf et al., 2004). In addition, a number of studies have pointed to the importance of parental investment in explaining diverse patterns of coping with social and economic disadvantage in adulthood (Furstenberg \& Hughes, 1995; Garmezy, 1985; Williams \& Kornblum, 1985).

Individual differences in temperament, attachment history, or traumatic interpersonal experiences appear to be critical factors in the degree to which young adults are able to garner and utilize social capital (Labouvie-Vief, Zhang, \& Jain, 2003; Mikulincer \& Shaver, 2001). A large proportion of youth who age out of foster care experience significant social capital deficits. Unconnected to committed and permanent adults in their lives they do not have the benefit of their birth parents' preparation for the adult world. By its very nature, foster care disrupts a youth's relationships with parents and extended family (Freundlich, 2009). A significant proportion of youth in care (particularly those living in out-of-home care situations such as residential treatment facilities and group homes) have few or no relationships or connections with parents, extended family members, or significant other adults who can provide the needed social support to make a successful transition to adulthood. Since the family unit is the central provider of lifelong relationships for children (Collins et al., 2008), foster youth without families do not have the comfort and security that belonging to a family network brings, and they lack models for creating resilient families, successful work lives, and strong cultural and ethnic identities. Importantly, as they approach adulthood they lack a vital safety net (Freundlich, 2009).

For older foster youth (ages 16-18) many child welfare agencies have long since discontinued their efforts to sustain the youth's relationships with family, reconnect youth with family members with whom contact has been lost over time, or assist youth in the developing of new relational networks with caring adults who can become "family" for youth as they enter emerging adulthood. In addition, because of their histories of child abuse and neglect, many youth preparing to leave foster care have physical, mental health, and developmental issues that elevate the importance of having caring committed adults available to support and guide them. They face the very real risk of aging out of qualification for the kind of help that most young people in modern societies require and receive as they establish themselves as independent young adults. The absence of strong "social scaffolding" in the lives of foster youth aging out of care is, no doubt, the critical predictor of the deleterious post-foster care outcomes that research has recently uncovered. The pursuit of enduring relationships, alongside the delivery of support services, is essential in "permanency oriented" child welfare services (Kerman \& Glasheen, 2009).

\section{Examining independent living programs}

Adolescents comprise a significant proportion of the foster care population in the United States. In 2006, $40 \%$ of children in foster care, comprising more than 190,000, were age 13 and older, and one-fifth of the children were older adolescents 16 and older. Over the past decade, the number of youth who age out of foster care has steadily increased. In 1998 17,000 youth "aged out" of foster care; by 2006 that 
number had increased by $50 \%$ to more than 26,000 youth (Kids are Waiting, 2009). In 2006, only 32,000 youth ages $12-20$ (or 14\%) lived in kinship family foster homes, while $35 \%$ of youth lived in group homes, institutions, or supervised independent living (U.S. Department of Health and Human Services (2008)). Freundlich (2009) notes that most youth in care live in group homes or institutions that do not provide opportunities for them to form the kind of lasting relationships with responsible adults that will help them move into adulthood.

The primary federal policy designed to assist youth with the transitioning out of foster care is the Foster Care Independence Act of 1999 (P.L. 106-169) (also known as the John H. Chafee Foster Care Independence Program (CFCIP)) which was intended to provide resources to states to develop programs and services to assist youth to establish independence after leaving care. Although CFCIPs provide a range of services that could be expected to prepare youth for the transition into adulthood on some functional dimensions, data have shown that only about two-thirds of eligible foster youth receive independent living services, with the quality of services varying significantly among states (Courtney, 2005). Furthermore, recent evaluations of independent living programs have found few impacts of CFCIPs on any measureable successful outcome for youth exiting care, leaving evaluators to conclude that there is no reason to believe that the services have a significant positive impact on any of the concrete indicators of successful transition to adulthood, such as educational attainment, employment, earnings, and avoidance of economic hardship, etc. (Courtney \& Zinn, 2008). These findings, combined with research findings reported earlier on child cognitive, emotional, and behavioral development, have led scholars to raise doubts whether a healthy or successful adult by any definition truly lives "independently" from others and is self-reliant in meeting their needs at any age, let alone age 18 (Iglehart, 1994; Reindal, 1999), and in child welfare circles the term 'independence' has recently been rejected as a policy and practice goal in favor of 'interdependence' as a synonym for self-reliance and interpersonal autonomy (Samuels \& Pryce, 2008).

Current child welfare philosophy is evolving to the position that successful transition from care is not only dependent on effective independent living skills, but is likely to be dependent on other aspects of child welfare policy implementation within the service system (Collins et al., 2008). The CFCIP and the programs interventions it supports do not specifically address assisting youth with reconnection to birth family, kin, and other significant other adults in their lives that will be the permanent safety net for them in the future (Collins et al., 2008). Research suggests that many youth exiting care have a need unforeseen in Chafee, i.e., enduring, supportive relationships (Kerman \& Glasheen, 2009). Iglehart (1995) notes that while independent living programs may offer the skills and knowledge needed for successful emancipation, it is not clear to what extent if any these programs can combat isolation and provide social support.

Although at one time it may have been a developmentally appropriate expectation for a young person to be on their own at age 18 , demographic evidence clearly indicates that in contemporary U.S. society young people are at a decided disadvantage if they lack the support of their family, or a family like unit (Aquilino, 1996; Avery \& Freundlich, 2009; Greeson \& Bowen, 2008; Goldscheider \& Goldscheider, 1993; Mendes, 2006). The failure of the foster care system, and independent living programs in particular, to prepare youth for connectedness to caring adults who can provide the supportive safety net as they explore adulthood is well-documented (e.g., Courtney et al., 2001; Georgiades, 2005; Mann-Feder \& White, 2003; McMillen, Rideout, Fisher, \& Tucker, 1997).

\section{Hearing from youth in care}

The search for permanence, including a reliable, lifelong parenting relationship and the opportunity to maintain contact with family and other important people, is described by youth and foster alumni as a core need to be balanced with the simultaneous need for independence (Samuels \& Pryce, 2008). Foster youth report rarely being involved in the decisions made about their short- or long-term care plans made for them (Unrau, 2006), and report having minimal, if any, control over maintaining core relationships with those to whom they are attached, most notably siblings (Harrison, 1999; Herrick \& Piccus, 2005; Mullender, 1999). In a study by Geenen and Powers (2007) current and former foster care youth emphasized the importance of taking part and having a say in the important decisions that impact their lives while in care, and the importance of caring long-term relationships with adults as they transition into adulthood. Former foster youth in the study reported the absence of caring, stable relationships in their lives and feelings of isolation and disconnectedness after exiting from care.

Caseworkers interviewed in the Geenen and Powers (2007) study recommended that questions regarding a foster youth's contact with birth parent(s) be revisited as the child becomes older and immediate concerns regarding safety or care-taking are less of a concern. The fact is that, although many child welfare systems have worked diligently to become more family centered, there remains a fundamental tension between child protection and family services (Collins et al., 2008) that undermines case work focused on reconnecting foster teens with their birth family and extended kin. McMillen and Tucker (1999) and Freundlich, Avery, Munson and Gertenzang (2006) raise excellent questions in wondering whether the child welfare system does not consider these family members as placement settings while the youth is still in care given the reported incidence of the extent of teens' reconnection with birth families after they leave care.

\section{Deleterious consequences of not achieving permanency}

Young people "aging out" of the child welfare system are undergoing a dual transition-one from the care of the system to autonomy and a second from childhood to adulthood-and they face numerous challenges in making this transition and many experience a range of negative outcomes (Shook, Vaughn, Litschge, Kolivoski, \& Schelbe, 2009). With overwhelming consistency, research suggests a startling constellation of increased risk factors for deleterious outcomes for youth aging out of foster care (Samuels \& Pryce, 2008). These include homelessness, early pregnancy, incarcerations, victimizations, and poverty (Barth, 1990; Courtney et al., 2005).

They quickly confront the harsh realities of life as an adult when they lack family relations and resources to support them (Courtney \& Hughes-Heuring, 2005; Freundlich, 2009; Shook et al., 2009), and are at high-risk of failing to meet even minimal levels of self-sufficiency and acceptable behaviors (McDonald, Allen, Westerfelt, \& Piliavin, 1993). Growing literature on foster youth outcomes illuminates a legitimate and very worrying concern that this population will experience their adulthood in the context of other public service systems and institutions (Samuels \& Pryce, 2008).

Two recent studies examining the experiences of youth following their exit from care found that these youth often struggle to complete their education, they frequently have significant health and mental health problems; they often are unemployed or underemployed and face poverty; and, as a group they are more socially isolated than their non-foster care peers (Courtney \& Dworsky, 2005; Pecora et al., 2005). They often have had contact with the justice system, live in socially disorganized neighborhoods that have higher rates of crime, experience substance abuse or mental health problems, leave the child welfare system with educational deficiencies, and are either unemployed or experience employment instability (Courtney et al., 2005; Vaughn, Shook, \& McMillen, 2008).

In a similar study Shook et al. (2009) found that youth often attach to 'deviant peer relationships' for support after exiting care, and youth with high levels of deviant peer affiliations were more likely to be 
fired from a job, to possess a diagnosis of antisocial personality disorder, to report higher levels of substance use, and to report being arrested than youth in the low or medium deviant peer affiliation groups. It is interesting to note that youth in the low deviant peer affiliation group had higher levels of family support and lower levels of neighborhood disorder than youth in the other two classes.

Foster youth also experience risk related to socio-emotional well being. A recent collaborative study by Harvard Medical School, Casey Family programs, and state agencies in Washington and Oregon found that former foster youth (ages 19-30) demonstrated post traumatic stress disorder rates up to twice as high as U. S. War Veterans (Pecora et al., 2005). In a comparative study, Lawrence, Carlson, and Egeland (2006) report foster youth in their sample indicated mental health and behavioral problems at rates more severe and more frequent than children from similar backgrounds (e.g., maltreatment) who were not placed in foster care. Even in studies where mental health is one of many outcome domains assessed, foster youth exhibit depression (Barth, 1990) and other psychological health problems at rates higher than in the general populations (Courtney \& Hughes-Heuring, 2005).

Numerous studies have shown that a high percentage of the homeless population on the streets of U.S. cities and towns are former foster care youth. For example, the Coalition for the Homeless reported that $60 \%$ of the homeless in New York City's Municipal Shelters have some history of foster care (Coalition for the Homeless, 1989). Shaffer and Canton (1984) in their study entitled "Runaway and Homeless Youth in New York City" found that $50 \%$ of the homeless young people who came to shelters had previously lived in a setting provided by the Child Welfare System, either in a foster home or a group home. In a study of 168 youth interviewed at Covenant House, the only youth shelter in New York City that accepts youth up to the age of 21 , it was found that $27 \%$ of them had spent time with a foster parent, and another $43 \%$ had spent time in foster group homes (Margetson \& Lipman, 1990). The National Foster Care Awareness Project reported that $40 \%$ of the nation's homeless were in foster care as children (National Association of Social Workers, 1991, October). In addition, in a survey conducted by the Chicago Coalition to the Homeless (1989) approximately $44 \%$ of homeless youth in Chicago report having been wards of the state. Furthermore, $46 \%$ of youth in runaway and homeless shelters in New Jersey reported that they had lived in New Jersey's foster care system in the previous year before they entered the shelter (data provided by New Jersey Division of Youth and Family Services, 2005).

Even more disturbing are results from research indicating that there is an intergenerational component to post-foster care homelessness that could well impact future generations as well. Homeless parents with a history of foster care are far more likely than other parents to have their own children in foster care. The National Alliance to End Homelessness conducted a survey of 21 housing provider organizations serving 1134 people in the programs during a two week period (Roman \& Wolfe, 1995). They found a drastic difference between homeless parents who grew up in foster care compared to homeless parents who did not grow up in foster care. Of those who had no foster care history and were homeless, $27 \%$ had at least one child who had a foster care history or was in foster care. Of those who had a foster care history and were homeless, $77 \%$ had at least one child who had a foster care history or was in foster care. Furthermore, one of the main precursors to any child entering foster care is having an active case open with the local Child Protection Service (CPS). The Institute for Children and Poverty (1997) examined the difference between homeless parents who did and did not grow up in foster care in New York City. They found that homeless parents without a history of foster care had active cases with CPS $29 \%$ of the time, while $19 \%$ of them had been previously homeless. On the other hand, homeless parents with a history of foster care had active cases with CPS $73 \%$ of the time, while $49 \%$ of them had been previously homeless.

\section{Conclusions regarding youth permanency and child welfare practice}

State and federal policy and support programs for youth aging out of care currently reflect a focus on preparing youth for "independent living" at age 18 and, until recently, have had a resultant lack of focus on developing and nurturing social capital prior to exit from care. In recent years there has been a growing awareness in the child welfare community (as evidenced in the literature and Federal grant RFPs) for the need to develop and implement policies and practices that ensure that youth have permanent committed relationships (adoption, guardianship, or other permanent outcomes) with adults before they leave care. This awareness has been accelerated by recent studies examining the post-foster care functioning of youth. These studies have provided convincing evidence that most youth who age out of foster care at 18 simply cannot make it on their own (Courtney et al., 2005; Courtney \& Dworsky, 2006; Furstenberg et al., 2005; Masten et al., 2006). They simply do not have the developmental maturity needed for successful entry into adult roles-especially youth with emotional, psychological, educational, and behavioral deficits resulting from early childhood experiences of abuse, neglect, and abandonment. Furthermore, there is a growing awareness that "independent living" is simply not a feasible option for the majority of youth in foster care who, unlike children who are not in foster care, lack the social scaffolding of stable family and community networks to support them (Voices Issue Brief, 2004).

Of particular concern to the child welfare community are youth aging out of foster care who are members of racial/ethnic minority groups, who comprise the majority of youth aging out of the system. The transition to 'independence' is particularly difficult for members of racial/ethnic minority groups because, in addition to personal identity exploration facing all emerging youth, these youth also must deal with identity issues in relation to their racial/ethnic heritageand these racial/ethnic identity domains are far more central for youth of color than for Caucasian youth (Phinney, 2006; Phinney \& Alipuria, 1990). For youth of color, a sense of membership in an ethnic, racial, or cultural group is an underlying issue that pervades and influences progress toward adulthood. In addition, these youth are frequently faced with discriminatory attitudes and evidence of their lower status and power in society which forces them to have to continually negotiate their sense of self in relation to other groups.

Another accelerator of this change in focus in the child welfare community is the consistent finding from studies of youth leaving care that they frequently connect to their families of origin, including residing with family members, after leaving foster care (Courtney \& Dworsky, 2006; Courtney et al., 2001; Iglehart \& Beccerra, 2002). Because homelessness is a significant threat to this population (Park, Metraux, Brodbar, \& Culhane, 2004) successful reunification with kin prior to exit from care may save these youth from being on the streets. Although family reunification is a core objective during the time children and youth are in care, the process of reunifying with families after leaving care is outside the scope of the child welfare system and often neglected in child welfare case planning. Because these postfoster care connections with family occur outside the child welfare system little is known about the process and outcomes of these reconnections (Collins et al., 2008).

While permanency has for decades been a core principle of child welfare work, its accepted definition within the child welfare community in terms of lifelong connections to kin and fictive kin appears to be gaining even greater currency (Collins et al., 2008). This is evidenced in a definition of permanency offered by Frey and Greenblatt (2005, p. 3) "Permanency" is about having an enduring family relationship that is safe and meant to last a lifetime; offers the legal rights and social status of full family membership; provides for physical, emotional, social, cognitive, and spiritual well being, and assures lifelong connections to birth and extended family, siblings, other significant 
adults, family history and traditions, race and ethnic heritage, culture, religion, and language. As early as 2000 Charles and Nelson (2000) discussed the importance of permanency for older adolescents in foster care in terms of the need to help youth make lasting connections to family, friends, and supportive networks, and Bussiere (2006) recommends integrated service plans that create permanency for older youth in terms of social supports, involving older youth as participants in their own permanency plans, identifying caring and supportive adults, exploring adoption options, and including family members in reunification plans. This "social capital" based definition of permanence is being driven by research that is just beginning to explore supportive networks and relationships as protective factors against many negative outcomes predicted for this population (Massinga \& Pecora, 2004; Perry, 2006; Propp, Ortega, \& NewHeart, 2003).

So, while general resilience and youth development literature outside of foster care contexts has long identified the benefits for youth of being connected to supportive adults, including its positive effects on self-esteem, psychological health, educational achievements, and social skill development (Massinga \& Pecora, 2004; Perry, 2006; Samuels \& Pryce, 2008), it is slowly developing as a priority focus in the child welfare literature and research. For example, the presence of at least one caring adult who offers social support and connectedness was identified as a protective factor for youth across a variety of risk conditions in studies by Fraser, Kirby, and Smokowski (2004) and Werner and Smith (2001), and studies by both Munson and McMillen (2007) and Ahrens, DuBois, Richardson, Fan, and Lozano (2008) showed that the presence of a natural mentor was significantly associated with foster youth's positive psychological outcomes.

Commensurate with this refocusing of the definition of youth permanence in child welfare has been the emergence of "best practice" strategies for attaining that permanence for youth aging out of care (National Resource Center for Foster Care and Permanency Planning \& Casey Family Services, 2004). The need to achieve and sustain family-based permanence for youth has prompted the development of child welfare practices that: help young people and their families cope with trauma, separation, and other challenges that can be barriers to reconnecting with kin and fictive kin; fully engaging youth in their own permanency planning; and serious reconsideration of the role of birth families as planning and permanency resources (Freundlich, 2009). Practice models are calling for youth-centered permanency planning teams: developing an individual team for each youth; asking the youth to identify important members of their own team; making the youth the central team player on the team; joining youth, birth parents, foster parents, family members, and other important adults together with professionals on the planning team; and facilitating a pro-active and continuous teaming process until youth reach permanence rather than episodic or crisis-driven meetings (Frey, 2009). In fact a variety of best practice model programs are using family teaming to involve youth and families in the permanency process (e.g., Permanency Teaming, Team Decision Making, Family Group Decision Making) (Kerman \& Glasheen, 2009). Frey (2009) further suggests fully involving youth in their own permanency plans by: asking them whom they love, who loves them, and to whom they want to be close and connected and asking them about blood and legal relatives, informal family members and other significant adults (teachers, coaches, mentors, etc.) they are close to.

\section{Promising practice model}

Attention is now turned to a model demonstration project, funded by the Children's Bureau (DHHS) during 2004-2008, that used a "social capital building" model to achieve permanence for teens at risk of aging out of care unconnected to permanent families. The program model is based in the assumption that the strongest, most secure, and most enduring "social capital" for aging out of care is a permanent nuclear and extended family achieved through adoption or other permanent commitment.

\subsection{Target population and approach}

The "Permanent Parents for Teens" project was a federally-funded demonstration effort funded through the Children's Bureau at the U.S. Department of Health and Human Services. The goal of the project was to find permanent adoptive parents for teens that were freed for adoption or to find committed permanent parents who would morally adopt teens who are not freed but in danger of discharge from foster care to homelessness. Using a multi-prong approach, the project tackled the problem of finding permanent homes for referred teens in the care of New York City's (NYC) foster care system before they were discharged from care. Target teens were currently residing in congregate care facilities in and around the NYC metropolitan area. The project utilized a partnership between NYC's Administration for Children's Services (ACS) and the grantee agency You Gotta Believe. Teens were referred to the project by staff at both the residential treatment facilities and the staff at the DSS.

\subsection{Project model}

The project model out stationed specialized staff at fifteen different residential facilities and group homes in and around New York City and Westchester County, including eight residential treatment centers and six group homes operated by NYC's Administration for Children's Services' (ACS) Office of Direct Care, and ACS's Office of Youth Development (OYD). Through the regular presence of project staff out stationed in these facilities they were able to regularly interact with facility social workers and resident teens and build up ongoing and consistent relationships in support of the youth. They were able to provide on-sight training about teen permanency, attend staff meetings for teens, and become a part of the management culture in these programs that facilitated their efforts to refocus planning efforts on youth permanency.

\subsection{Child-specific recruitment approach}

The project accepted referrals of teens residing in these, and other, congregate care facilities. Specialized case-work activity focused on a child-specific recruitment approach called Permanency Action Recruitment Teams (PART). PART meetings were convened for all teens referred to the project, unless a permanent resource had already been identified for them at the time of referral. The PART meeting brought together all parties involved in the permanency planning process for the teen, including individuals in the teen's life who could potentially be a permanency resource for them, and focused on goal setting and strategy development for achieving permanency for teens prior to their exit from care. The PART meetings were attended by the teen, the teen's social worker, facilities staff, and other individuals involved in the teen's life (relatives, acquaintances, etc.). The meetings were led by the family permanency advocates, a teen permanency advocate (both project staff members), and the teen themselves. Prior to a PART meeting the family permanency advocate would work diligently with the teen to identify significant others (kin, fictive kin, friends, acquaintances) in their life with whom they had a positive constructive relationship and who could potentially be a permanent resource for them. This included scouring their case files for potential names of individuals who previously had been foster parents, friends, teachers, etc. The staff member then contacted those individuals and invited them to take part in the PART meeting, made home visits to people who couldn't make a day-time meeting, offered to arrange to get people who know the teen to special meetings, and reached out to relatives not previously considered as a permanency resource. 
In cases where teens were unable to identify potential permanency resources in their lives at the time of referral, project workers immediately involved the teens in opportunities for sharing time and space with prospective permanent parents including: hiring the teen as a training consultant and panelist during the Adopting Older Kids And Youth (A-OKAY) classes; hiring a teen to work around the office where waiting families often came to go through books, look at pictures, use the Internet, etc.; invited waiting teens to all agency events such as holiday parties (Halloween and Christmas), summer picnics, trips to amusement parks and minor league baseball games, etc., which offer waiting teens and parents an opportunity to share the same time and space; and, setting up individualized special events that provide an opportunity to bring together youth and prospective parents, such as talent shows, craft events, etc.

\subsection{Parent education and training}

The grantee agency You Gotta Believe, a licensed foster care agency, held certification trainings in eight different locations in and around the New York City area convenient to all families and at after-hour and weekend times convenient to families. These trainings were heavily advertised throughout the community and were open to anyone who heard the message and decided to attend the trainings, included those who were invited by a project worker, a friend or neighbor, or invited by a teen. Attendance at the trainings was completely voluntary and anyone who walked through the door was welcomed to participate.

These trainings formed a critically important role in the project model since they focused on parent preparation for teen placement in the home. The rotating nature of the ten separate classes (30h of training) meant that families could join the trainings at any time and start the classes in any order, providing maximum flexibility for prospective families. These trainings were designed to prepare new families for unconditional commitment to teens and to increase the receptivity of trained families for youth placement in the future. Through these trainings the project was able to license the family, place the teen into the licensed home, and then transfer a fully NYS-approved home to the agency that has the teen in its care until the teen was legally adopted.

Four of the ten A-OKAY classes were specifically focused on older child adoption: Class 1: Experienced Parent Panel: the panel brought together three or four experienced parents who had adopted teens to talk about both the rewards and challenges of raising teens permanently and about making lasting commitments. Class 2: Youth-in-Care or Former Youth-in-Care Panel: this panel brought together three or four youth in care or former youth in care to talk about how important lifelong permanency is for them. Class 3: Adolescent Development: this very unique workshop was developed by You Gotta Believe staff to look at the developmental needs of adolescents. The class addresses the uniqueness of moving into a home from a differently structured congregate care facility, the internal conflict within the teen about wanting to attach to their new family, and their struggle for independence. Class 4: Behavior and Unconditional Commitment: this class addresses how important it is to make a lifetime commitment to a teen regardless of their behavior. It helps prospective parents understand that so called "bad" behavior needs to be treated, and that re-abandoning the child should never be part of that treatment. The class stresses the importance of treating any teen's "bad" behavior with the identical commitment to that offered a birth child.

\subsection{Professional trainings}

Project staff also provided ongoing trainings for staff at the congregate care facilities where they were out stationed. These trainings emphasized the urgent need to get every teen into a permanent home before their discharge from foster care. Information was shared during these trainings about the strong connection between aging out, homelessness, and other deleterious outcomes for youth. The trainings were designed to empower staff at all levels to help explore the constructive adults in the teens' lives, including opening these staffers up to the possibility of being a parent themselves. The trainings emphasized that one of the primary obstacles keeping teens out of permanent homes is worker attitudes and beliefs about the possibility of permanent parents for older teens.

Project staff also worked with New York City's Office of Youth Development and other agencies serving New York City teens to encourage them to allow project staff to bring in panels to talk to their youth about permanency. These panels, organized through the Project's "Speak-Out Bureau", addressed a primary concern many teens have-a strong belief that nobody wants them. The panels included teens and young adults who were adopted as teens, certified prospective parents who wanted to adopt teens, as well as new parents who recently received the placement of a teen. The goal of the panels was to help teens understand that not only are teens getting permanent homes-many from the constructive adults already in their lives-but that there are parents who come forward to do this as well. The project's 'Speak-Out Bureau' gave staff, parents, and teens an opportunity to share their stories with the rest of the child welfare community. It was believed that the stories of these individuals would have more impact on the target audience than training alone, and that personal testimony would be a powerful influence on attitudes, beliefs, and behaviors.

\subsection{Post-placement services}

After a teen was successfully placed in a home by project efforts, an experienced adoptive parent (Shadow Worker) was assigned to the family to make regular contact with them for as long as the family needed help and guidance. In addition, the staff held ongoing monthly Parent Support Groups for any parent who had a teen placed by the project in their home, and Shadow Workers and Permanency Advocates Parents fielded calls from parents or teens whenever needed. This project element filled a major child welfare service gap by providing critical post-placement support services that were significant in securing the stability of the teen placement.

\section{Evidence-based practice}

The project model was a highly successful one in terms of teen permanency outcomes and evaluation data indicate that the strategy of home finding used in this project, i.e., exploring currently existing kin, fictive kin, and other significant relationships already existing in the teen's life at the time of referral, is a highly successful recruitment strategy for older teens in care. In addition, evaluation results indicate that the dual project strategy of child-specific recruitment and focused parent training (A-OKAY training and certification) was primarily responsible for the high teen placement rate in this demonstration project.

\subsection{Teen permanency placements}

A total of 199 teens were referred to the project during the funding period. The majority of referred teens were living in institutional settings, residential treatment facilities (75.9\%) and group homes (18.6\%). The average age of referred teens was 15.7 years and, on average, these teens had spent 7.4 years in foster care and 2.7 years in their current congregate care facility. Many teens referred to the project had multiple and severe special needs, including emotional, behavioral, learning, psychiatric, developmental, and medical/physical needs. The success of project efforts is indicated in the evaluation result that 98 of the 199 referred teens (or almost 50\%) were permanently placed into homes by end of the project period. 


\subsection{Adoptive parent training}

The evaluation design was unique in that it allowed for a natural experiment to occur regarding the A-OKAY parent trainings. This natural experiment provided strong and convincing evidence of the success of a project model in which child-specific recruitment is paired with targeted parent training. The grantee agency, You Gotta Believe, conducts their A-OKAY training for both project parents (i.e., potential permanency resources identified by referred teens) and other parents who are either referred to the agency for foster care training or who turn up at the trainings simply interested in learning more about adoption and fostering. Documentation was made of all people who started the AOKAY training at any of the agency's training sites during the 4 years of the grant. Individuals were then classified into people who knew a specific teen needing placement at the start of their training, and people who did not know a specific teen they were interested in at the time of training. In evaluating the data presented below it is important to note that the project's outreach to both the general public unconnected to a specific teen, and to anyone else who might know a teen, is to actively encourage them to take the A-OKAY trainings. The project did not screen anyone who turned up to the trainings, and everyone from the community was welcomed. In fact, outreach activities advertised the classes to the general public on the You Gotta Believe radio program, TV program, and literature to come and "Learn about Adopting Teens".

In evaluating the data presented below stark differences are found in training completion rates, home study completion rates, licensing rates, and teen placement rate between the two groups (Table 1).

Throughout the 4 years of the project a total of 1143 people walked through the A-OKAY training doors and participated in an orientation session. Approximately 449 (or 39\%) of those people completed the $30 \mathrm{~h}$ of training, 190 (or 17\%) completed the training and got licensed, and 120 (or $10 \%$ ) completed the training, got licensed and got a teen placed with them through the project efforts. A little more than $10 \%$ of the people who walked through our door had a teenager placed with them.

The interesting contrast, however, and one that has significant implications for teen recruitment efforts, is the difference that emerges in training outcomes when people are classified by whether they knew a specific teen at the time of training initiation or not. Of those people who did not start the training with a particular teen in mind ( 987 or $86 \%$ of all people who walked through the doors), 324 (or 33\%) completed the $30 \mathrm{~h}$ of training, 106 (or $11 \%$ ) completed the home study, and only 37 (4\%) got a teen placed with them. In stark contrast, of those people who started training knowing a specific teen (154 or $14 \%$ of all people who walked through the doors), 125 (or $81 \%$ ) completed the $30 \mathrm{~h}$ of training, 84 (or $54 \%$ ) completed a home study, and 83 (or 53\%) got the teen placed with them. The numbers in the last column of the table tell an important story. Overall $63 \%$ of the people who completed the training and their home study had a teen placed with them, but when you classify those parents by whether they had a particular teen in mind at the initiation of the training, only $35 \%$ of those who did not know a teen competed the home study and had a teen placed with them while $99 \%$ of those who knew a specific teen at the time of training initiation completed the home study and had a teen placed in the home.

These comparative data really help to dispel several myths about recruitment and training. The first myth is that if you recruit someone a teen knows, you should not ask them to take a 30-hour parent preparation class about how important it is to remain unconditionally committed because that would turn parents off. The evaluation data indicate that $81 \%$ of the people who walk through the training doors who knew a teen completed the entire 10 -week, $30 \mathrm{~h}$ training. Another myth is that there are a large number of people from the teens' lives that are not qualified to be permanent parents. The data indicate that over half of the parents were qualified enough to complete a home study and get licensed.

\subsection{Other project elements contributing to this 'promising practice' model}

One of the most important strengths of the project was the background of project staff. All staff had significant personal experience with older child adoption (i.e., they had been adopted from care as teens themselves and/or were adoptive parents of older youth) and consequently had deep personal knowledge of the teen placement process. Project staff were selected based on particular personality characteristics of motivation, empathy, the ability to engender trust and confidence, and excellent management skills which facilitated continuity and follow-up in service delivery. In addition, staff were selected based on their firm belief that every child in care deserves a home and that there is a home for every child in care. This belief was unwavering in all staff members and resulted in the significant success of the project in terms of goal outcomes. Furthermore, the staff management model used on this project greatly contributed to enabling the talented staff members to do their job effectively. The fact that staff were out stationed at the congregate care facilities rather than operating out of a central office enabled them to develop close and ongoing relationships with both the teens and congregate care staff members, facilitated time management, and allowed them to meet the needs of teens and parents at convenient locations and on their own time schedules.

\section{Other collaborative efforts}

Farmer (2008) reports on another similar child-specific recruitment effort involving You Gotta Believe at Children's Village. The project serviced 69 teen residents (ranging in age from 13 to 20), all of whom had been in residential care for at least 5 years and were, more or less, poised to age out of the system without leaving care. They hired two permanency specialists to find homes for these youths. The approach they used was to find matches with individuals teens already knew and felt a special connection with, such as an aunt, uncle, for former foster parent by asking the teens themselves, pouring over the case records, and actively searching for leads. They worked with You Gotta Believe using a range of matchmaking efforts, such as using teens as panelists for educational seminars and orientations geared to prospective foster parents, but the most effective recruiting strategy was simply talking to the youth about anyone in their past or in their current sphere of connections with whom they might like to live. A critical part of this recruitment process was the 10-week A-OKAY parental training and licensing course offered by You Gotta Believe.

Table 1

\begin{tabular}{|c|c|c|c|c|c|}
\hline & Number of entrants & Completed training & Home study completed & Teen placed in home & $\begin{array}{l}\text { Percent completing training, } \\
\text { the home study, and with } \\
\text { a teen placement }\end{array}$ \\
\hline Total & 1143 & $449(39 \%)$ & $190(17 \%)$ & $120(10.4 \%)$ & $63 \%$ \\
\hline Did not know teen & 987 (86\%) & $324(33 \%)$ & $106(11 \%)$ & $37(4 \%)$ & $35 \%$ \\
\hline Did know teen & $154(14 \%)$ & $125(81 \%)$ & $84(54 \%)$ & $83(53 \%)$ & $99 \%$ \\
\hline
\end{tabular}




\section{Current evolving "family-finding" technologies}

Recent technological improvements have made it easier to locate missing family and important adults assumed lost (Louisell, 2009). The Homecoming Project began in 2003 as a five-year Federal demonstration project. In addition to seeking adoptive families the project also had the explicit goal of strengthening participating youth's connections to caring adults and the larger community by engaging in child-specific recruitment efforts. An analysis of project records and administrative data shows that $51 \%$ of these youth in the Homecoming Project achieved permanency during the funding period (Skrypek \& Gerrard, 2009). Family-finding efforts for youth in residential care in Santa Clara County, CA located more than 220 relatives for eight youth by doing only 9 hours of family search work (Campbell et al., 2003, p. 15). In 2006 the California Permanency for Youth Project (CPYP) (Friend, 2009) created the Emancipated Youth Connections Project (EYCP) to assist twenty young adults who left the foster care system without sustained relationships to a caring adult. This 18 -month project was tremendously successful in finding family or other caring adults to be lifelong connections. Data available for 19 of the 20 participants showed that: 139 new permanent connections were made with biological family members and 42 new permanent connections were made with nonbiological family members. These results demonstrate that permanency can be attained for older youth in foster care through successful childspecific recruitment efforts such as those reported in this paper.

\section{References}

Ahrens, K. R., DuBois, D. L., Richardson, L. P., Fan, M. Y., \& Lozano, P. (2008). Youth in foster care with adult mentors during adolescence have improved adult outcomes. Pediatrics, 12(2), e246-e252.

Allen, J. P., \& Hauser, S. T. (1996). Autonomy and relatedness in adolescent-family interactions as predictors of young adults' states of mind regarding attachment Development and Psychopathology, 8, 793-809.

Arnett, J. J. (2007). Adolescence and emerging adulthood: A cultural approach, 3rd Ed. Upper Saddle River, NJ: Pearson-Prentice Hall.

Arnett, J. J., \& Tanner, J. L. (Eds.). (2006). Emerging adults in America coming of age in the 21st century Washington, DC: American Psychological Association.

Arnett, J. J., \& Taber, S. (1994). Adolescence terminable and interminable: When does adolescence end? Journal of Youth and Adolescence, 23(5), 517-537.

Aquilino, W. S. (2006). Family relationships and support systems in emerging adulthood. In J. J. Arnett \& J.L. Tanner (Eds.), Emerging adults in America coming of age in the 21st century Washington, DC: American Psychological Association.

Aquilino, W. S. (1996). The returning child and parental experience at midlife. In C. D. Ryff \& M.M. Seltzer (Eds.), The parental experience in midlife Chicago: The University of Chicago Press.

Avery, R. J., \& Freundlich, M. (2009). You're all grown up now: Termination of foster care support at age 18. Journal of Adolescence, 32, 247-257.

Baker, W. (2000). Achieving success through social capital: Tapping the hidden resources in your personal and business networks. San Francisco: Jossey-Bass.

Barth, R. (1990). On their own: The experience of youth after foster care. Child and Adolescent Social Work, 7(5), 419-440.

Bell, K. L., Allen, J. P., Hauser, S. T., \& O'Connor, T. G. (1996). Family factors and young adult transitions: Educational attainment and occupational prestige. In J. A. Graber \& J. Brooks-Gunn (Eds.), Transitions through adolescence: Interpersonal domains and context (pp. 345-366). Hillsdale, NJ: Erlbaum.

Bussiere, A. (2006). Permanence for older youth. Family Court Review, 44, 231-243.

Campbell, K., Castro, S., Houston, N., Koenig, D., Roberts, T., Rose, J., et al. (2003, Fall). Lighting the fire of urgency: Families lost and found in America's child welfare system. Permanency planning today (pp. 15). New York, NY: National Resource Center for Foster Care and Permanency Planning, Hunter College School of Social Work.

Center for the Study of Law and Social Policy (2008). Fostering connections to success and increasing adoptions act will improve outcomes for children and youth in foster care. Center for Law and Social Policy from http://www.clasp.org/publications/ FINAL-FCSAIAAct1-pager.pdf

Charles, K., \& Nelson, J. (2000). Permanency planning: Creating life-long connections: What does it mean for adolescents? Tulsa, OK: National Resources Center for Youth development.

Coalition for the Homeless. (1989). Blueprint for solving New York's homeless crisis. New York City: A report to Mayor Dinkins pp. 101.

Cohen, P., Kasen, S., Chen, H., Hartmark, C., \& Gordon, K. (2003). Variation in patterns of developmental transitions in the emerging adulthood period. Developmental Psychology, 39(4), 657-669.

Coleman, J. S. (1990). Foundations of social theory. Cambridge, MA: Harvard University Press.

Collins, M. E., Paris, R., \& Ward, R. L. (2008). The permanence of family ties: Implications for youth transitioning from foster care. American Journal for Orthopsychiatry, 78(1), 54-62

Cooney, T. M., \& Kurz, J. (1996). Mental health outcomes following recent parenta divorce: The case of young adult offspring. Journal of Family Issues, 17, 495-513.
Courtney, M. E. (2005). Youth aging out of foster care. Network on transitions to adulthood policy brief. The network of transitions to adulthood, Vol. 19. Retrieved from http://wispolitics.com/1006/Chapin_Hall_Executive_Summary.pdf

Courtney, M. E., \& Dworsky, A. (2005). Midwest evaluation of the adult functioning of former foster youth: At age 19. Wisconsin's Premier Political News Service. Retrieved from http://wispolitics.com/1006/Chapin_Hall_Executive_Summary.pdf

Courtney, M. E., \& Dworsky, A. (2006). Early outcomes for young adults transitioning from out-of-home care in the USA. Child and Family Social Work, 11, 209-219.

Courtney, M. E., Dwosrky, A., Ruth, G., Havlick, J., \& Bost, N. (2005). Midwest evaluation of the adult functioning of former foster youth: Outcomes at age 19. Chicago, IL: Chapin Hall Center for Children at the University of Chicago.

Courtney, M. E., \& Hughes-Heuring, D. (2005). The transition to adult hood for youth "aging out" of the foster care system. In D. W. Osgood, E. M. Foster, C. Flanagan, \& G. R. Ruth (Eds.), On their own without a net: The transition to adulthood for vulnerable populations Chicago, IL: University of Chicago Press.

Courtney, M. E., Piliavin, I., Grogan-Kaylor, A., \& Nesmith, A. (2001). Foster youth transitions to adulthood: A longitudinal view of youth leaving care. Child Welfare, $80(6), 685-717$

Courtney, M. E., \& Zinn, A. (2008). Evaluation of the Life Skills Training Program Los Angeles County, California: Final report. Administration for children \& families. Retrieved from http://www.acf.hhs.gov/programs/opre/abuse_neglect/chafee/ reports/eval_lst/eval_lst.pdf

Farmer, A. (2008, Summer). Making the right match: One agency's efforts to move hard-to-place teens into foster homes offers lessons for the entire system. Child Welfare Watch, 16, 11-14.

Fraser, M. W., Kirby, L. D., \& Smokowki, P. R. (2004). Risk and resilience in childhood. In M. W. Fraser (Ed.), Risk and resilience in childhood: An ecological perspective, 2 nd Ed. Washington, DC: NASW Press.

Freundlich, M. (2009, Spring). Adolescents in the child welfare system improving permanency and preparation for adulthood outcomes. In T. LaLiberte \& E. Snyder (Eds.), Permanency or aging out - Adolescents in the child welfare system. Minnesota: Center for Advanced Studies in Child Welfare, University of Minnesota School of Social Work.

Freundlich, M., Avery, R. J., Munson, S., \& Gertenzang, S. (2006). The meaning of permanency in child welfare: Multiple stakeholder perspectives. Children and Youth Services Review, 28, 741-760.

Frey, L. (2009). Permanence or aging out? A matter of choice. In T. LaLiberte \& E. Snyder (Eds.), Permanency or aging out - Adolescents in the child welfare system. Minnesota: Center for Advanced Studies in Child Welfare, University of Minnesota School of Social Work.

Frey, L., \& Greenblatt, S. (2005). Call to action: An integrated approach to youth permanency and preparation for adulthood. New Haven, CT: Casey Family Services with California Permanency for Youth project, Casey Family Programs, and Jim Casey Youth Opportunities Initiative, Inc.

Friend, B. (2009). California Permanency for Youth project: An overview. In T. LaLiberte \& E. Snyder (Eds.), Permanency or aging out - Adolescents in the child welfare system. Minnesota: Center for Advanced Studies in Child Welfare, University of Minnesota School of Social Work.

Furstenberg, F. F., \& Hughes, M. E. (1995). Social capital and successful development among at-risk youth. Journal of Marriage and Family, 57, 580-592.

Furstenberg, F. F., Rumbaut, R. G., \& Settersten, R. A. (2005). On the frontier of adulthood. In R. A. Settersten, F. F. Furstenberg, \& R. C. Rumbaut (Eds.), On the frontier of adulthood. Chicago: University of Chicago Press.

Garmezy, N. (1985). Stress resistant children: The search for protective factors. In J. Stevenson (Ed.), Recent research in developmental psychopathology. Oxford: Pergamon Press.

Geenen, S., \& Powers, L. E. (2007) "Tomorrow is another problem": The experiences of youth in foster care during their transition into adulthood. Children and Youth Services Review, 29, 1085-1101.

Georgiades, S. D. (2005). Emancipated young adults' perspectives on independent living programs. Families in Society, 86(4), 503-510.

Goddard, R. D. (2003). Relational networks, social trust, and norms: A social capital perspective on students' chances of academic success. Educational Evaluation and Policy Analysis, 25(1), 59-74.

Goldscheider, F., \& Goldscheider, C. (1993). Leaving home before marriage: Ethnicity, familism, and generational relationships. Madison, WI: University of Wisconsin Press.

Greenberg, J., Schimel, J., Martens, A., Solomon, S., \& Pyszczynski, T. (2001). Sympathy for the devil: Evidence that reminding Whites of their morality promotes more favorable reactions to White racists. Motivation and Emotion, 25, 113-133.

Greeson, J. K. P., \& Bowen, N. K. (2008). "She holds my hand" The experiences of foster youth with their natural mentors. Children and Youth Services Review, 30, 1178-1188.

Harrison, C. (1999). Young people, being in care and healthy identity. In J. Masson, C. Harrison, \& A. Pavlovic (Eds.), Lost and found: Making and remaking working partnerships with parents of children in the care system. London: British Agencies for Adoption and Fostering.

Herrick, M. A., \& Piccus, W. (2005). Sibling connections: The importance of nurturing sibling bonds in the foster care system. Children and Youth Services Review, 27(7), 845-861.

Iglehart, A. P., \& Beccerra, R. (2002). Hispanic and African American youth: Life after foster care emancipation. Social Work with Multicultural Youth, 11, 79-107.

Iglehart, A. P. (1995). Readiness for independence: Comparison of foster care, kinship care, and non-foster care adolescents. Children and Youth Services Review, 17, 417-432.

Iglehart, A. P. (1994). Adolescents in foster care: Predicting readiness for independent living. Children and Youth Services Review, 16, 159-169.

Institute for Children \& Poverty (1997). Homelessness: The foster care connection (pp. 16). Updated, 1997. 
Kerman, B., \& Glasheen, L. K. (2009). The central role of permanence in improving outcomes for youth aging out of foster care. In T. LaLiberte \& E. Snyder (Eds.), Permanency or aging out - Adolescents in the child welfare system. Minnesota: Center for Advanced Studies in Child Welfare, University of Minnesota School of Social Work.

Kids are Waiting (2009). State-by-state facts. Retrieved from http://kidsarewaiting.org/ publications/statefacts

Labouvie-Vief, G., Zhang, F., \& Jain, E. (2003). Affect complexity and affect optimization: Cross-sectional validation and longitudinal examination. Unpublished manuscript, Wayne State University, Detroit, MI

Lawrence, C. R., Carlson, E. A., \& Egeland, B. (2006). The impact of foster care on development. Developmental Psychopathology, 18, 57-76.

Louisell, M. J. (2009). Six steps to find a family: A practice guide to family search and engagement (FSE). Retrieved from http://centerforchildwelfare.fmhi.usf.edu/kb/ Prgprac/Six\%20Steps\%20to\%20Find\%20a\%20Family.pdf

Mann-Feder, V. R., \& White, T. (2003). Facilitating the transition from placement to independent living: Reflections from a program of research. International Journal of Child E' Family Welfare, 4, 198-204.

Margetson, N., \& Lipman, C. (1990). Children at risk: The impact of poverty, the family and street on homeless and runaway youth in New York City. Presentation delivered at the National Symposium on Youth Victimization, April 27, 1990 (pp. 1-2). New York: Covenant House.

Massinga, R., \& Pecora, P. J. (2004). Providing better opportunities for older children in the child welfare system. The Future of Children, 14(1), 151-173.

Masten, A. S., Obradovic, J., \& Burt, K. B. (2006). Resilience in emerging adulthood: Developmental perspectives on continuity and transformation. In J. J. Arnett \& J. L. Tanner (Eds.), Emerging adults in America coming of age in the 21st century (pp. 173-190). Washington, DC: American Psychological Association.

McDonald, T. P., Allen, R. L., Westerfelt, A., \& Piliavin, I. (1993). Assessing the long-term effects of foster care: A research synthesis. Madison, WI: Institute for Research on Poverty.

McMillen, J. C., Rideout, G. B., Fisher, R. H., \& Tucker, J. (1997). Independent-living services: The views of former foster youth. Families in Society, 78(5), 471-479.

McMillen, J. C., \& Tucker, J. (1999). The status of older adolescents at exit from out-ofhome care. Child Welfare, 78, 339-360.

Mendes, P. (2006). From dependence to interdependence: Towards better outcomes for young people leaving state care. Child Abuse Review, 15, 110-126.

Metzger, S. (2006). Permanency for teens: New York City's emerging policy. Voices For America's Children, Casey Family Services, Issue Brief. Retrieved from http://www. caseyfamilyservices.org/pdfs/casey_teens.pdf

Mikulincer, M., \& Shaver, P. R. (2001). Attachment theory and intergroup bias: Evidence that priming the secure base schema attenuates negative reactions to out-groups. Journal of Personality and Social Psychology, 81, 97-115.

Mullender, A. (Ed.). (1999). We are family: Sibling relationships in placement and beyond. London: British Agencies for Adoption and Fostering.

Munson, M. R., \& McMillen, J. C. (2007, January). Older youth in foster care and their natural mentors. Paper presented at the 11th Annual Conference of the Society for Social Work and Research, San Francisco.

National Association of Social Workers (1991, October). Findings from a national survey of shelters for runaway and homeless youth: Executive summary of key NASW survey findings. Survey supported by the U.S. Department of Health E' Human Services. Grant No. 90K2124 (pp. 1).

National Resource Center for Foster Care and Permanency Planning \& Casey Family Services (2004). Framework for permanency for young people framework. Retrieved from http://www.hunter.cuny.edu/socwork/nrcfcpp/info_services/permanencefor-young-people.html

New Jersey Division of Youth and Family Services (2005). Date provided to You Gotta Believe, Inc.

Park, J. M., Metraux, S., Brodbar, B., \& Culhane, D. P. (2004). Public shelter admission among young adults with child welfare histories by type of service and type of exit. Social Service Review, 78, 284-303.

Pecora, P. J., Kessler, R. C., Williams, J., O'Brien, K., Downs, C. A., \& English, D. (2005). Improving family foster care: Findings from the northwest foster care alumni study. Seattle, WA: Casey Family Programs.

Perry, B. L. (2006). Understanding social network disruption: The case of youth in foster care. Social Problems, 53(3), 371-391.

Phinney, J. (2006). Ethnic identity explorations in emerging adulthood. In J. J. Arnett \& J.L. Tanner (Eds.), Emerging adults in America coming of age in the 21st century. Washington, DC: American Psychological Association.
Phinney, J., \& Alipuria, L. (1990). Ethnic identity in college students from four ethnic groups. Journal of Adolescence, 13, 171-184.

Propp, J., Ortega, D. M., \& NewHeart, F. (2003). Independence or interdependence: Rethinking the transition from "ward of the court" to adulthood. Families in Society: The Journal of Contemporary Human Services, 82(2), 259-266.

Putnam, R. D. (2000). Bowling alone. New York: Simon \& Schuster.

Putnam, R. D. (1995). Bowling alone: America's declining social capital. Journal of Democracy, 6, 65-78.

Pyszczynski, T., Greenberg, J., \& Solomon, S. (1999). A dual-process model of defense against conscious and unconscious death-related thoughts: An extension of terror management theory. Psychological Review, 106, 835-845.

Roman, N. P., \& Wolfe, P. (1995). Web of failure: The relationship between foster care and homelessness. National Alliance to End Homelessness. Retrieved from http://www. endhomelessness.org/files/1285_file_Web_of_Failure.pdf

Reilly, T. (2003). Transition from care: Status and outcomes of youth who age out of foster care. Child Welfare, 82, 727-746.

Reindal, S. M. (1999). Independence, dependence, interdependence: Some reflections on the subject and personal autonomy. Disability and Society, 14(3), 353-367.

Samuels, G., \& Pryce, J. (2008). What doesn't kill you makes you stronger: Survivalists self-reliance as resilience and risk among adults aging out of foster care. Children and Youth Services Review, 30(10), 1198-1210.

Sandefur, R. L., \& Lauman, E. O. (1998). A paradigm for social capital. Rationality and Society, $10,481-501$.

Scharf, M., Mayseless, O., \& Kivenson-Baron, I. (2004). Adolescents' attachment representations and developmental tasks in emerging adulthood. Developmental Psychology, 40(3), 430-444.

Scholte, R. H. J., van Lieshout, C. F. M., \& van Aken, M. A. G. (2001). Perceived relationa support in adolescence: Dimensions, configurations, and adolescent adjustment. Journal of Research on Adolescence, 11, 71-94.

Schultz, L. H., \& Selman, R. L. (1998). Ego development and interpersonal development in young adulthood: A between-model comparison. In P. M. Westenberg, A. Blasi, \& L. D. Cohn (Eds.), Personality development: Theoretical, empirical, and clinical investigations of Loevinger's conception of ego development (pp. 181-202). Mahwah, NJ: Erlbaum.

Shaffer, D., \& Canton, C. L (1984). Runaway and homeless youth in New York City. New York City. Study funded by a grant from the Ittleson Foundation and the New York State Office of Mental Health (pp. 57).

Shook, J. J., Vaughn, M. G., Litschge, C., Kolivoski, K., \& Schelbe, L. (2009). The importance of friends among foster youth again out of care: Cluster profiles of deviant peer affiliations. Children and Youth Services Review, 31, 284-291.

Skrypek, M., \& Gerrard, M. D. (2009). Finding permanency homes for teens in care: Results of a federal demonstration project. In T. LaLiberte \& E. Snyder (Eds.), Permanency or aging out - Adolescents in the child welfare system. Minnesota: Cente for Advanced Studies in Child Welfare, University of Minnesota School of Social Work.

Steinberg, L. (2005). Cognitive and affective development in adolescence. Trends in Cognitive Sciences, 9(2), 69-74.

Unrau, Y. A. (2006). Research on placement moves: Seeking the perspective of foster children. Children and Youth Services Review, 29(1), 122-137.

U.S. Department of Health and Human Services. (2008). The AFCARS Report: Preliminary FY 2006 Estimates as of January 28 (14). Retrieved from http:/ www.acf.hhs.gov/programs/cb/stats_research/afcars/tar/report14/htm

Vaughn, M. G., Shook, J. J., \& McMillen, J. C. (2008). Aging out of foster care and legal involvement: Towards a typology of risk. Social Service Review, 82(3), 419-446.

Voices Issue Brief (2004, August). Effective approaches to supporting youth aging out of foster care. Washington, DC: Voices for America's Children. Retrieved from http:// www.vociesforamericaschildren.org

Werner, E. E., \& Smith, R. S. (2001). Journeys from childhood to midlife: Risk, resilience, and recovery. Ithaca, NY: Cornell University Press.

Williams, T., \& Kornblum, W. (1985). Growing up poor. Lexington, MA: Lexington Books.

Young, M. H., Miller, B. C., Norton, M. C., \& Hill, E. J. (1995). The effect of parental supportive behaviors on life satisfaction of adolescent offspring. Journal of Marriage and Family, 57(3), 813-821. 